\title{
A Questão Ambiental no CRAS: Promoção de Qualidade de Vida e Sustentabilidade*
}

\author{
Kelly Daiane Savariz Bôlla ${ }^{1}$ \\ Geraldo Milioli ${ }^{1}$ \\ ${ }^{1}$ Universidade do Extremo Sul Catarinense, SC, Brasil. \\ ${ }^{1}$ Universidade do Extremo Sul Catarinense, SC, Brasil.
}

Resumo: Este estudo teórico tem como objetivo discutir a relevância de abordar a questão ambiental nas oficinas com famílias desenvolvidas no âmbito dos Centros de Referência de Assistência Social (CRAS), equipamentos de proteção social básica do Sistema Único de Assistência Social (SUAS), no Brasil. Visa ainda propor reflexões acerca do trabalho social que pode ser desenvolvido pelas equipes de referência do CRAS, compostas obrigatoriamente por profissionais da Psicologia, com vistas à promoção da qualidade de vida e à sustentabilidade. Esta discussão fundamenta-se nas normativas do CRAS, no referencial teórico das Ciências Ambientais, da Psicologia Social e das áreas da Psicologia voltadas à sustentabilidade. A crise ambiental é uma problemática atual, complexa e interdisciplinar, com grande potencial de impactar o ambiente de vida de todos, sobretudo, daqueles que se encontram em situação de vulnerabilidade social. O reconhecimento, pelo SUAS, da necessidade de abordar o direito ao meio ambiente saudável nas oficinas realizadas no CRAS permite que sejam trabalhadas relevantes questões ambientais, de acordo com o diagnóstico do território de abrangência do equipamento e o interesse das famílias atendidas. Conclui-se que o desenvolvimento do trabalho social sobre a questão ambiental, a partir da reflexão, da sensibilização e da difusão de conhecimentos, saberes e técnicas, é uma possibilidade de intervenção transformadora, capaz de empoderar a população para a busca por melhorias da qualidade ambiental do território e para o desenvolvimento de um modo de vida mais sustentável e saudável, além de poder contribuir para o fortalecimento da autonomia e do sentimento de comunidade.

Palavras-chave: Qualidade de vida, Psicologia Social, Psicologia Ambiental, Desenvolvimento Sustentável, Mudança social.

* O presente trabalho foi realizado com apoio da Coordenação de Aperfeiçoamento de Pessoal de Nível Superior - Brasil (CAPES). 


\title{
The Environmental Issue in CRAS: Perspectives for Promotion of Quality of Life and Sustainability
}

\begin{abstract}
This theoretical study aims to discuss the relevance of addressing the environmental issue in workshops with families developed in the Social Assistance Reference Centers (CRAS), basic social protection equipment of the Unified Social Assistance System (SUAS), in Brazil. It also aims to propose reflections about the social work that can be developed by the reference teams of CRAS, composed necessarily by Psychology professionals, with a view to the promotion of quality of life and sustainability. This discussion is based on CRAS regulations, the theoretical reference of the environmental sciences, Social Psychology and the areas of Psychology focused on sustainability. The environmental crisis is a current problem, complex and interdisciplinary, with great potential to impact the living environment of all, especially those who are in situations of social vulnerability. The recognition by SUAS of the need to address the right to a healthy environment in the workshops developed atCRAS allows relevant environmental issues to be discussed, according to the diagnosis of the area covered by the equipment and the interest of the families attended. It is possible to conclude that the development of social work on the environmental issue, from the reflection, awareness and knowledge and techniques dissemination, is a possibility of transformative intervention capable of empowering the population to search for improvements in the environmental quality of the territory and for the development of a more sustainable and healthy way of life, besides being able to contribute to the strengthening of the autonomy and the sense of community.
\end{abstract}

Keywords: Quality of life, Social Psychology, Environmental Psychology, Sustainable Development, Social Change.

\section{La Cuestión Ambiental en el CRAS: Perspectivas para Promover la Calidad de Vida y la Sostenibilidad}

Resumen: Este estudio teórico tiene como objetivo discutir la relevancia de abordar el tema ambiental en talleres con familias desarrollados dentro de los Centros de Referencia de Asistencia Social (CRAS), equipo de protección social básica del Sistema Unificado de Asistencia Social (SUAS), en Brasil. También tiene como objetivo proponer reflexiones sobre el trabajo social que pueden desarrollar los equipos de referencia de CRAS, compuestos necesariamente por profesionales de la Psicología, con miras a promover la calidad de vida y la sostenibilidad. Esta discusión se basa en las normas de CRAS, el marco teórico de las ciencias ambientales, la Psicología Social y las áreas de Psicología centradas en la sostenibilidad. La crisis ambiental es un problema actual, complejo e interdisciplinario, con un gran potencial para impactar el ambiente de vida de todos, especialmente de aquellos en situación de vulnerabilidad social. El reconocimiento por parte de SUAS de la necesidad de abordar el derecho a un medio ambiente saludable en los talleres de CRAS permite abordar cuestiones ambientales relevantes, de acuerdo con el diagnóstico del territorio de cobertura del equipo y el interés de las familias atendidas. Se concluye que el desarrollo del trabajo social sobre el tema ambiental, desde la reflexión, la sensibilización y la difusión de conocimientos, saberes y técnicas, es una posibilidad de intervención transformadora, capaz de empoderar a la población para buscar mejoras de calidad del medio ambiente y del desarrollo de una forma de vida más sostenible y saludable, y pueden contribuir al fortalecimiento de la autonomía y el sentimiento de comunidad.

Palabras clave: Calidad de vida, Psicología Social, Psicología Ambiental, Desarrollo Sostenible, Cambio Social. 
O direito ao meio ambiente ecologicamente equilibrado dos cidadãos brasileiros, instituído pela Constituição Federal de 1988, é violado cotidianamente por decisões pessoais ou políticas e econômicas que desrespeitam o meio ambiente, bem de uso comum do povo e essencial à qualidade de vida de todos.

A instalação de grandes corporações nacionais e internacionais, para extração de bens naturais e seu beneficiamento, produzem diversos danos ambientais nos territórios e no entorno, desde o início do processo até o descarte de rejeitos. Os efeitos do modelo de agricultura dependente de fertilizantes químicos e agrotóxicos ultrapassa as fronteiras do espaço produtivo e polui a água, o ar e solo. A instalação de usinas produtoras de energia, cujo potencial de destruição da biodiversidade e da sociodiversidade é alarmante. Estes são exemplos de como as decisões corporativas, particulares ou políticas impactam o meio ambiente, de onde provêm o ar, a água, os alimentos e demais serviços ecossistêmicos dos quais toda humanidade depende para sua sobrevivência.

Descarte e vazamentos constantes de resíduos poluidores na água, no solo e na atmosfera, desmatamento, erosão do solo, extermínio de comunidades indígenas são algumas das violações do direito ao meio ambiente ecologicamente equilibrado que têm ocorrido em nome do "progresso". No entanto, o ônus da degradação do meio ambiente recai sobre todas as nações, embora os países em crescimento econômico enfrentem maiores ameaças à vida.

De acordo com o artigo 225 da Constituição Federal Brasileira de 1988, todo cidadão brasileiro tem direito ao meio ambiente ecologicamente equilibrado, embora, na prática, esse direito não tem sido garantido.

Um avanço importante na direção de promoção da cultura da sustentabilidade, capaz de incitar comportamentos sustentáveis no seu cotidiano e exigir o compromisso político com a sustentabilidade, foi o reconhecimento do direito ao meio ambiente saudável como uma das temáticas a serem trabalhadas em oficinas com famílias nos Centros de Referência de Assistência Social (CRAS), unidades públicas do Sistema Único de Assistência Social (SUAS), implementado a partir 2004 no Brasil. O SUAS é um sistema público que organiza, de forma descentralizada, os serviços socioassistenciais no Brasil. Por meio de serviços, programas, projetos e benefícios, executa a Política Nacional de Assistência Social (PNAS), apro- vada em 2004, e visa à proteção social e a garantia de direitos de pessoas e famílias em situação de vulnerabilidade social. O CRAS é o equipamento responsável pela proteção básica e a execução do Serviço de Proteção e Atendimento Integral à Família (PAIF) que consiste na realização, dentre outras intervenções, de oficinas com famílias, por meio das quais são discutidos os direitos humanos e os meios de acessá-los. Entre esses direitos, está o direito ao meio ambiente saudável. Entende-se que trabalhar o direito ao meio ambiente saudável no CRAS é uma oportunidade de refletir sobre a relação entre ser humano e natureza, entender o território a partir de uma perspectiva sistêmica e contribuir para a promoção da sustentabilidade no âmbito local com ressonância global.

Deste modo, a equipe de referência do CRAS, de caráter interdisciplinar, que inclui assistente social e psicólogo (a), tem um importante papel de incluir a questão ambiental na compreensão do seu território de abrangência e no empoderamento da população atendida para a busca por melhoria do ambiente e para o desenvolvimento de um modo de vida mais sustentável, com consequências positivas ao seu bem-estar e qualidade de vida.

Visto que a sustentabilidade no âmbito do SUAS é um tema que se encontra à margem da discussão científica acerca desta política pública e, considerando o compromisso social da Psicologia, este artigo visa contribuir com algumas diretrizes para o planejamento do trabalho social com famílias desenvolvido no CRAS, de modo a abranger a complexidade da relação entre ser humano e ambiente e de promover transformações na realidade.

\section{Percurso metodológico}

Este estudo teórico tem como objetivo discutir a relevância da abordagem da temática do meio ambiente saudável como direito de todos no âmbito dos CRAS, utilizando-se de normativas do referido equipamento, de referencial teórico das Ciências Ambientais, da Psicologia Social e das áreas da Psicologia voltadas à relação humana com o meio ambiente, como a Psicologia Ambiental e a Ecopsicologia, abrangendo a interface entre a vulnerabilidade social e os impactos ambientais. Esta pesquisa também tem como objetivo propor reflexões e elencar possibilidades de atuação dos profissionais que compõem a equipe de referência do CRAS quanto ao trabalho social que pode ser desenvolvido com vistas à 
promoção da qualidade de vida e da sustentabilidade naquele equipamento. Visto a carência de referencial teórico-metodológico sobre esta questão, são apontadas temáticas com potencial de promover mudanças no modo de vida das famílias e na qualidade ambiental do território.

Este artigo surge da inter-relação entre a experiência de trabalho da primeira autora como integrante da equipe de referência de um CRAS, apoiado nas referências da Psicologia Social, e a experiência de pesquisa e prática no campo das Ciências Ambientais - especialmente da educação ambiental e das ecovilas ${ }^{1}$. A partir desse entrecruzamento de conhecimentos, são exprimidas algumas reflexões sobre as possibilidades de intervenção acerca da questão ambiental que podem ser executadas nos CRAS, com respaldo das normativas do equipamento e condizentes com o compromisso social da Psicologia.

\section{O Sistema Único de Assistência Social - SUAS}

A Assistência Social no Brasil é dever do Estado e um direito de todo cidadão de que dela necessitar. De acordo com a PNAS (Brasil, 2004), a Assistência Social brasileira passa a ter uma nova concepção através da Constituição Federal de 1988, inserindo-se no campo dos direitos, da universalização dos acessos e da responsabilidade estatal.

A Lei Orgânica da Assistência Social (LOAS), publicada em 1993, dispõe sobre a organização da assistência social no País, define objetivos, princípios, diretrizes, gestão e institui benefícios, serviços, programas e projetos destinados à proteção e ao enfrentamento da vulnerabilidade ou risco social e pessoal. $\mathrm{O}$ art. $1^{\circ}$ da LOAS (Lei No $8.742,1993$ ) assegura que:

A assistência social, direito do cidadão e dever do Estado, é Política de Seguridade Social não contributiva, que provê os mínimos sociais, realizada através de um conjunto integrado de ações de iniciativa pública e da sociedade, para garantir o atendimento às necessidades básicas.
A Política Nacional de Assistência Social, aprovada em 2004, marcou o início do processo de configuração do SUAS (Pereira, 2010). De acordo com o Ministério de Desenvolvimento Social e Combate à Fome - MDS (BRASIL, 2004), esta iniciativa traduziu o cumprimento das deliberações da IV Conferência Nacional de Assistência Social, realizada em 2003, e a materialização das diretrizes da LOAS.

O SUAS é um sistema público que organiza, de forma descentralizada, os serviços socioassistenciais no Brasil. Com um modelo de gestão participativa, o SUAS articula os esforços e recursos dos três níveis de governo para a execução e o financiamento da PNAS, envolvendo diretamente as estruturas e marcos regulatórios nacionais, estaduais, municipais e do Distrito Federal (Brasil, 2005). O SUAS foi criado com o compromisso de romper com a lógica tradicional do assistencialismo e da fragmentação de ações (Brasil, 2015). Para tal, promove o acesso a benefícios, programas, projetos e serviços socioassistenciais aos cidadãos de que deles necessitarem, visando promover transformações nos territórios em situação de vulnerabilidade e nas famílias atendidas. Coordenado pelo MDS, o Sistema é composto pelo poder público e sociedade civil, que participam do processo de gestão compartilhada.

O SUAS organiza as ações da assistência social em dois tipos de proteção social: a proteção social básica e a proteção social especial.

A proteção social básica tem como objetivos prevenir situações de risco por meio do desenvolvimento de potencialidades e aquisições e o fortalecimento de vínculos familiares e comunitários. [...]. A proteção social especial tem por objetivos prover atenções socioassistenciais a famílias e indivíduos que se encontram em situação de risco pessoal e social, por ocorrência de abandono, maus tratos físicos e, ou, psíquicos, abuso sexual, uso de substâncias psicoativas, cumprimento de medidas socioeducativas, situação de rua, situação de trabalho infantil, entre outras (Brasil, 2005, p. 18).

\footnotetext{
${ }^{1}$ Ecovilas são comunidades humanas intencionais sustentáveis. A Rede Global de Ecovilas (Global Ecovillage Network, 2011) designa ecovilas como comunidades urbanas ou rurais de pessoas esforçadas em desenvolver um ambiente social favorável causando o menor impacto possível à vida e à natureza. Para isso, integram aspectos da permacultura, agricultura orgânica, bioconstrução, produção de energia alternativa, práticas comunitárias etc.
} 
Proteção Social pode ser entendida como as formas institucionalizadas que as sociedades instituem para proteger parte ou o conjunto de seus membros que se encontram em certas condições da vida natural ou social, tais como a velhice, a doença, o infortúnio, as privações. A Proteção Social abrange as formas seletivas de distribuição e redistribuição de bens materiais, como a comida e o dinheiro, e de bens culturais, como os saberes, que permitem a sobrevivência e a integração na vida social (Di Giovanni, 1998).

De acordo com a PNAS (Brasil, 2004, p. 31) "a proteção social deve garantir as seguintes seguranças: segurança de sobrevivência (de rendimento e de autonomia); de acolhida; de convívio ou vivência familiar", se diferenciando do modelo assistencialista e de ações fragmentadas.

Compõe o público usuário da PNAS, cidadãos e grupos que se encontram em situações de vulnerabilidade e riscos, tais como: famílias e indivíduos com perda ou fragilidade de vínculos de afetividade, pertencimento e sociabilidade; identidades estigmatizadas em termos étnicos, culturais e sexuais; desvantagem pessoal resultante de deficiências; exclusão pela pobreza e/ou no acesso às demais políticas públicas; uso de substâncias psicoativas; diferentes formas de violência advinda do núcleo familiar, grupos e indivíduos; inserção precária ou não inserção no mercado de trabalho formal e informal; estratégias e alternativas diferenciadas de sobrevivência que podem representar risco pessoal e social. Atua, portanto, com famílias desprovidas das condições básicas para vida digna e cidadã, idosos, pessoas com deficiência, população em situação de rua, indígenas, quilombolas, adolescentes em conflito com a lei, entre outros (Brasil, 2004).

Além dos serviços, o SUAS engloba a oferta de Benefícios Assistenciais, prestados a públicos específicos de forma articulada aos serviços, a fim de contribuir para a superação de situações de vulnerabilidade (Brasil, 2004).

\section{o Centro de Referência de Assistência Social: perspectivas e potencialidades}

O CRAS é uma unidade pública estatal de assistência social responsável pela proteção social básica no SUAS, cujos objetivos são prevenir situações de risco por meio do desenvolvimento de potencialidades e aquisições, e o fortalecimento de vínculos fami- liares e comunitários e da ampliação do acesso aos direitos de cidadania.

No ano de 2015, em todo Brasil havia mais de 7500 CRAS (Brasil, 2015).

De acordo com a PNAS (Brasil, 2004, p. 33), a proteção social básica:

Destina-se à população que vive em situação de vulnerabilidade social decorrente da pobreza, privação (ausência de renda, precário ou nulo acesso aos serviços públicos, dentre outros) e, ou, fragilização de vínculos afetivos - relacionais e de pertencimento social (discriminações etárias, étnicas, de gênero ou por deficiências, dentre outras).

O conceito de vulnerabilidade envolve três fatores principais: exposição, suscetibilidade e capacidade de enfrentamento frente ao risco (Mendes, \& Tavares, 2011). A vulnerabilidade social é a condição em que se encontra parte da população brasileira, caracterizada por acesso precário a equipamentos e oportunidades sociais, econômicas e culturais oferecidos pelo Estado, mercado e sociedade (Padoin, \& Virgolin, 2010). Para os autores, "a vulnerabilidade social é um conceito que tem sua origem na área dos Direitos Humanos. Refere-se a grupos ou indivíduos fragilizados, jurídica ou politicamente, na promoção, proteção ou garantia de seu direito à cidadania" (Padoin, \&Virgolin, 2010, p. 1).

De caráter preventivo, protetivo e proativo, os benefícios, serviços, programas e projetos ofertados pelo CRAS atuam na proteção social básica de acordo com a vulnerabilidade social apresentada. Estes deverão se articular com as demais políticas públicas locais, de forma a garantir a continuidade das ações desenvolvidas e o protagonismo das famílias e indivíduos atendidos, com objetivo de contribuir para superação das condições de vulnerabilidade e a prevenção das situações que indicam risco potencial (Brasil, 2004, p. 34-35).

Designado para promoção da proteção social básica, o CRAS é a unidade de assistência social responsável pelo desenvolvimento exclusivo do PAIF. O serviço atua com indivíduos e famílias em seu território, visando à orientação e ao convívio sociofamiliar e comunitário.

O trabalho social com famílias desenvolvido no CRAS deve considerar a existência de diferentes 
arranjos familiares e compreender que a família tem importante função de prover a proteção e a socialização dos seus membros; de se constituir como referência de valores, de vínculos afetivos e sociais; de identidade grupal, além de ser mediadora das relações dos seus membros com outras instituições sociais e com o Estado (Brasil, 2004).

A PNAS tem como base o conceito da matricialidade sociofamiliar, que se refere à centralidade da família como núcleo social fundamental para a efetividade de todas as ações e serviços da política de assistência social. O SUAS reconhece as fortes pressões que os processos de exclusão sociocultural geram sobre as famílias brasileiras, acentuando suas fragilidades e contradições. Portanto, as ações da política de assistência social são centradas na família, como espaço privilegiado e insubstituível de proteção e socialização primárias, provedora de cuidados aos seus membros, mas que precisa também ser cuidada e protegida (PNAS, 2004). Através da adoção do princípio da matricialidade sociofamiliar, as famílias são vistas como um espaço de mobilização à participação e ao protagonismo, caracterizando-se como agentes de mudança da realidade social (Brasil, 2009, p. 13).

A composição da equipe de referência é regulamentada pela Norma Operacional Básica de Recursos Humanos do SUAS (NOB-RH/SUAS) e depende do número de famílias referenciadas ao CRAS. A categoria de assistente social é obrigatória em todas as unidades e, por meio da Resolução no 07, de 20 de junho de 2011, a categoria de psicólogo(a) passou a integrar obrigatoriamente as equipes de referência de proteção social básica e proteção social especial de média e alta complexidade do SUAS. Portanto, a inserção de psicólogo(a) no CRAS foi tornada obrigatória. Outros profissionais de nível superior que compõe o SUAS e podem fazer parte da equipe do CRAS são: pedagogos, sociólogos, antropólogos ou profissionais com formação compatível com a intervenção social realizado pelo PAIF (Brasil, 2009).

O PAIF, operacionalizado pelos técnicos de nível superior, abrange um conjunto de procedimentos realizados com a população atendida com o objetivo de proteger seus direitos, apoiá-las no desempenho da sua função de proteção e socialização de seus membros, e assegurar o convívio familiar e comunitário, a partir do seu reconhecimento como sujeitos de direitos (Brasil, 2012, p. 11). O PAIF materializa-se a partir do desenvolvimento de ações de caráter pre- ventivo, protetivo e proativo, por meio das seguintes ações que o caracterizam: acolhida; oficinas com famílias; ações comunitárias; ações particularizadas; e encaminhamentos.

Dentre as ações do PAIF, as oficinas com famílias são importantes instrumentos de aquisição de informação, promoção de reflexão, troca de experiências e convivência, fortalecimento dos laços comunitários, com potencial de transformação da família, da comunidade e da sociedade. As oficinas com famílias propiciam a problematização e reflexão crítica de questões muitas vezes naturalizadas no contexto familiar e das situações vividas em seu território. Desenvolvem-se a partir de encontros organizados com grupos de, preferencialmente, sete a quinze representantes ou responsáveis pelas famílias e outros membros, coordenadas pelos técnicos de nível superior da equipe do CRAS.

Por meio das publicações em dois volumes de "Orientações Técnicas sobre o Serviço de Proteção e Atendimento Integral à Família - PAIF: Trabalho Social com Famílias" (Brasil, 2012), o SUAS lança diretrizes para o desenvolvimento do trabalho social com famílias operacionalizado no CRAS. O segundo volume deste manual de orientações, com o intuito de subsidiar o trabalho da equipe de referência, sugere que as oficinas com as famílias promovam a discussão reflexiva e troca de experiências sobre temas que se agrupam em três eixos: vida familiar, vulnerabilidades e potencialidades do território e informações sobre direitos.

O trabalho social sobre direitos envolve a informação e reflexão sobre os direitos civis, políticos, sociais, culturais, econômicos e ambientais de cada cidadão e os meios de acessá-los. O SUAS (Brasil, 2012) sugere que sejam trabalhados nas oficinas: o direito à transferência de renda, à documentação civil básica, à cultura, ao esporte e lazer, direitos das crianças e adolescentes, direito das mulheres, direitos dos idosos, direitos das pessoas com deficiência, direito à alimentação e nutrição adequada e direito ao meio ambiente saudável.

\section{A sustentabilidade e a busca interdisciplinar por ambientes melhores de se viver}

A preocupação com o meio ambiente se popularizou na segunda metade do século $\mathrm{XX}$, com o apoio das pesquisas científicas que confirmaram os alertas 
do movimento ambientalista sobre os riscos de destruição ambiental decorrentes da intensa intervenção humana nos sistemas ecológicos.

Em 1972, foi realizada a "Primeira Conferência das Nações Unidas sobre o Meio Ambiente” em Estocolmo, colocando em pauta a sobrevivência da humanidade e defendendo a educação ambiental como uma atividade de importância estratégica na promoção da qualidade de vida.

Alguns anos depois, o relatório desenvolvido pela Comissão Mundial Sobre Meio Ambiente e Desenvolvimento (CMMAD, 1988), publicado em 1987 no livro Nosso Futuro Comum, também chamado "Relatório Brundtland", denunciou os impactos ambientais antropogênicos e suas ameaças aos sistemas naturais e, portanto, à vida, e estabeleceu diretrizes para o desenvolvimento sustentável. Este conceito surgiu pela primeira vez neste relatório, como alternativa ao modelo de desenvolvimento sinônimo apenas de crescimento econômico, responsável pelo uso excessivo de bens naturais e pela poluição oriunda do processo de produção de bens materiais e do posterior descarte dos rejeitos.

Posteriormente, em 1992, a cidade do Rio de Janeiro sediou a Rio-92, Conferência das Nações Unidas sobre Desenvolvimento e Meio Ambiente, em que 173 chefes de estado e de governo aprovaram a Agenda 21, documento que reuniu propostas e objetivos para reverter o processo de degradação do ambiente.

Atualmente, décadas depois desses marcos na trajetória de alerta sobre a urgência da preservação do meio ambiente, poucos avanços ocorreram efetivamente na reorientação das sociedades para o cuidado com o planeta.

Poluição atmosférica, hídrica e do solo, erosão, urbanização desordenada, desmatamento, a crescente geração de resíduos sólidos em todo o mundo e os baixos índices de reciclagem na maioria dos países, as mudanças climáticas, são alguns entre tantos outros sintomas da crise ambiental.

Frente a essa problemática, Leff $(2009$, p. 7) afirma que ao longo das últimas décadas: "Apesar da consciência ecológica que foi se gerando e das políticas públicas em matéria de meio ambiente e desenvolvimento sustentável, a crise ambiental segue avançando, se acentuando e complexificando". Destaca-se a diminuição anual de massa florestal, as altas emissões de dióxido de carbono, associadas às mudanças climáticas, que evidencia a ineficácia das políticas derivadas do Protocolo de Kyoto (Leff, 2009).

Decorrentes da degradação do ambiente natural, problemas de saúde têm afetado a população humana. Indicadores mundiais e pesquisadores de todo o mundo alertam para a correlação entre fatores ambientais e a saúde do ser humano, cujos riscos à saúde vão desde os originários de poluição química na água, no ar e no solo, ou riscos sanitários até implicações na saúde mental e na qualidade de vida.

Destacam-se os efeitos prejudiciais às vias respiratórias causados pela poluição do ar, bem como os danos à pele devido à destruição da camada de ozônio. Também é uma ameaça a possibilidade de intoxicação por mercúrio, enxofre e outros produtos químicos lançados no meio ambiente por indústrias; há ainda a contaminação através da ingestão de alimentos produzidos por uma agricultura com alto consumo de agrotóxicos, pesticidas e fertilizantes químicos. Somam-se a estes a falta de acesso à água potável e ao saneamento básico (Rattner, 2009).

Nesse cenário, a tecnologia ambiental ou tecnologia verde não é suficiente para mitigar os impactos negativos do estilo de vida insustentável no ambiente. São imprescindíveis mudanças no modo como o ser humano se relaciona com a natureza.

Para reduzir as ameaças à sobrevivência e viabilizar o desenvolvimento sustentável, a CMMAD (1988) defende a necessidade de modificações no sistema econômico mundial que promovam a diminuição da desigualdade social e o aumento da proteção ambiental.

A CMMAD (1988, p. 9) explica que "a humanidade é capaz de tornar o desenvolvimento sustentável - de garantir que ele atenda às necessidades do presente sem comprometer a capacidade de as gerações futuras atenderem também às suas" e "[...] para haver um desenvolvimento sustentável é preciso atender às necessidades básicas de todos e dar a todos a oportunidade de realizar suas aspirações de uma vida melhor".

O desenvolvimento sustentável é contrário ao modelo de desenvolvimento econômico hegemônico pautado no crescimento econômico sem limites, que exaure os recursos naturais e desconsidera o fato de a Terra não ser ilimitada, tanto no que se refere à disposição dos recursos naturais no ambiente quanto à capacidade de os sistemas naturais suportar danos ambientais (Cavalcanti, 2004).

Carvalho (2013) salienta que para a ideologia do crescimento econômico ilimitado a qualquer custo, a 
pessoa tem um papel absolutamente secundário e os ecossistemas, a não ser que se tornem fontes de lucro, são absolutamente dispensáveis. Nesse modelo de desenvolvimento, tanto o meio ambiente quanto as pessoas são colocados a serviço do lucro, sendo, portanto, relegados a segundo plano.

Diferentemente, o desenvolvimento sustentável busca conciliar a economia, a ecologia e qualidade de vida das pessoas, de modo que os impactos decorrentes dos sistemas produtivos não ultrapassem as possibilidades dos sistemas ecológicos de absorvê-los.

Nesse sentido, sustentabilidade não se restringe à fauna e flora, mas incorpora o ser humano no ambiente de vida. Por isso, é um conceito complexo que integra várias dimensões: sustentabilidade social, sustentabilidade econômica, sustentabilidade ecológica, sustentabilidade espacial e sustentabilidade cultural (Sachs, 2007). Nesse sentido, a sustentabilidade implica maior equidade na distribuição de renda e de bens, superação das trocas desiguais entre países pobres e ricos, limitação do uso de combustíveis fósseis e de outros recursos facilmente esgotáveis ou danosos ao ambiente, redução do volume de resíduos e de poluição, promoção da reciclagem e da autolimitação do consumo material, melhor distribuição territorial dos assentamentos humanos e das atividades econômicas, amparo à continuidade cultural dos povos e à busca por soluções adequadas às especificidades de cada contexto socioecológico (Sachs, 2007).

Relacionada às várias esferas da vida humana, a sustentabilidade está em posição contrária ao desequilíbrio ambiental, bem como à competição, à ganância, à destruição, ao domínio, ao individualismo, entre outros valores e atitudes da sociedade capitalista (Brandão, 2007).

A sustentabilidade relembra o ser humano de sua condição biológica que o faz interdependente de todos os seres existentes na natureza, onde cada ser ocupa um lugar importante para manter o equilíbrio dinâmico do planeta, de onde deriva todas as condições necessárias para sua existência, inclusive influenciando a saúde e a qualidade de vida humana.

A CMMAD (1988, p. 16) destacou que, com vistas à promoção do desenvolvimento sustentável, "as mudanças que desejamos nas atitudes humanas dependem de uma ampla campanha de educação, debates e participação pública”. A necessidade dessas estratégias ainda é atual. Somente com a participação das pessoas é possível construir um mundo mais justo e sustentável, que preserve a natureza e promova saúde e qualidade de vida.

As mudanças precisam ocorrer primeiramente na consciência das pessoas, para que, só assim, possam ter comportamentos que levem ao desenvolvimento sustentável (Braun, 2005). Mesmo as decisões políticas e econômicas que extrapolam o poder de escolha individual da população podem ser impactadas pelo povo quando este tem informação e consciência ecológica.

É sabido que os impactos humano-ambientais são gerados de modo desproporcional pelos seres humanos e que deve haver a atribuição de responsabilidades específicas às classes, grupos e governos que intervêm maciçamente no uso da natureza (Loureiro, 2012).

A exploração e a contaminação ambiental têm decorrido da produção incessante de bens supérfluos que enriquecem pequena parcela da população, o que leva à compreensão de que a natureza também é oprimida por um sistema econômico e político gerador de concentração de renda e desigualdades sociais. No entanto, não se pode diminuir o papel da consciência ecológica da população na construção de um mundo sustentável. Através da compreensão de que é necessário reverter o atual processo de destruição do ambiente - imprescindível à saúde e ao bem-estar, por meio do conhecimento de práticas sustentáveis, vislumbra-se a possibilidade de maior participação social na construção de sociedades sustentáveis, justas e que respeitam os direitos humanos.

No campo da sustentabilidade, cada vez mais a Psicologia está se inserindo para contribuir no desenvolvimento de uma nova relação entre ser humano e natureza e na busca de ambientes melhores para se viver. A Psicologia Ambiental, surgida em torno de 1950, contribuiu com a crescente demanda por entendimento das relações entre comportamentos humanos e os ambientes sociofísicos, com ênfase no estudo de ambientes construídos.

A Psicologia Ambiental tem sua origem na interdisciplinaridade entre a Psicologia e áreas externas, sendo as três grandes disciplinas com as quais faz interface: 1) da Arquitetura e Planejamento Urbano, 2) Geografia e 3) Ciências Biológicas e Ecológicas. A Psicologia Ambiental ainda se aproxima da Educação Ambiental, principalmente no que se refere à contribuição que pode dar no que se refere às representações sociais do ambiente, bem como se relaciona com a Psicologia da Percepção e a Psicologia Social (Pinheiro, 1997). 
Além da Psicologia Ambiental, a Ecopsicologia surge nesse cenário de interlocução entre Psicologia e Ecologia com uma outra perspectiva, estudando os efeitos psicológicos da relação humana com a natureza e os benefícios do contato com ambientes naturais. A Ecopsicologia entende a atual produção humana do supérfluo a partir da destruição do essencial - ou seja, da natureza - como um processo psicopatológico de autodestruição, enquanto alienação humana de sua conexão com o ambiente (Roszak, 1995). A Ecopsicologia pode ser inserida em programas educacionais, projetos ambientais e comunitários que visam promover mudanças de paradigmas insustentáveis e uma nova relação entre natureza e seres humanos, da qual possa se originar desenvolvimento pessoal e consciência ecológica.

A Psicologia Social Latino-Americana, embora não tenha como objeto de estudo e intervenção a relação entre ser humano e ambiente, integra as discussões acerca da importância da sustentabilidade. Essa área da Psicologia tem como objetivo eliminar a alienação social e psicológica que afeta a vida das pessoas e gera opressão e tem como desafio a busca por uma "ação transformadora através da participação consciente dos indivíduos que constituem uma comunidade" (Lane, 2000, p. 60). A ideia de desenvolvimento como crescimento econômico que permeia a sociedade e gera a ilusão de progresso atrelado ao consumo e à aceitação da destruição da natureza para mantê-lo, gera diversos impactos a toda a sociedade.

A Psicologia Social Comunitária, uma área da Psicologia Social, se atém ao estudo do psiquismo humano decorrente do modo de vida na comunidade, "visa ao desenvolvimento da consciência dos moradores como sujeitos históricos e comunitários, através de um esforço interdisciplinar que perpassa o desenvolvimento dos grupos e da comunidade" (Góis, 1993). A Psicologia Social Comunitária atua por meio de ação pedagógica-formativa com enfoque preventivo na perspectiva de desenvolver projetos políticos que resultem na mudança na vida cotidiana das pessoas (Freitas, 2012). Seu compromisso com a transformação social da população através da conscientização, do desenvolvimento da autonomia e autogestão e da melhoria da qualidade de vida se dá na atuação com grupos para, dentre outros objetivos, discutir cidadania, participação, questões culturais e ambientais, estilos de vida saudáveis.
Todas elas, sobretudo a Ecopsicologia e a Psicologia Social Latino-Americana, onde se insere a Psicologia Social Comunitária, embora com suas particularidades e ênfases, problematizam questões sociais naturalizadas, questionam a sociedade capitalista e seus impactos às pessoas e ao meio ambiente e discutem a importância de transformações da sociedade consumista, desigual e produtora de sofrimento psíquico para modelos de sociedades mais justas e promotoras de bem-estar, o que vai ao encontro da sustentabilidade.

Pinheiro (1997, p. 1) afirma que "a Psicologia precisa se engajar na análise e no encaminhamento de soluções para os problemas ambientais, pois estes são, de fato, problemas humano-ambientais". Os impactos ambientais são determinados pela ação humana e social, ou seja, se originam de comportamentos humanos insustentáveis e estes, por sua vez, decorrem de uma visão de mundo e de ser humano reducionista.

É fundamental ao profissional de Psicologia ter uma visão complexa do ser humano e do meio ambiente, entendendo homens e mulheres em suas múltiplas dimensões e integrados à natureza. Compreender o meio ambiente de modo complexo requer percebê-lo enquanto ambiente natural e construído, físico, químico e biológico, que está em relação com toda a vida em sociedade. Inerente à relação entre ecologia e a sociedade, destacam-se as implicações do crescimento econômico ilimitado sobre a natureza e a sociedade, o consumismo e seus impactos sobre o ambiente e às pessoas, e a necessária busca por técnicas e hábitos sustentáveis.

\section{O direito ao meio ambiente saudável reconhecido no âmbito do SUAS: avanços na promoção da cultura da sustentabilidade}

O direito ao meio ambiente saudável foi instituído no Brasil pela Constituição da Federal de 1988, em seu artigo 225, que assegura: "todos têm direito ao meio ambiente ecologicamente equilibrado, bem de uso comum do povo e essencial à sadia qualidade de vida, impondo-se ao Poder Público e à coletividade o dever de defendê-lo e preservá-lo para as presentes e futuras gerações" (Brasil, 1988).

A problemática ambiental é de suma relevância na contemporaneidade frente às persistentes degradações ambientais. No âmbito do SUAS, o reconhecimento do direito ao meio ambiente saudável como uma das temáticas a serem trabalhadas em oficinas 
com famílias nos CRAS constitui-se em uma possibilidade de intervenção que contribui para a melhoria da qualidade de vida das famílias e da qualidade ambiental das comunidades, com consequências positivas à sustentabilidade global.

De acordo com as "Orientações Técnicas sobre o Serviço de Proteção e Atendimento Integral à Família - PAIF: Trabalho Social com Famílias" (Brasil, 2012, p. 32), objetiva-se, no trabalho social com grupos de família, na temática de direitos ambientais:

[...] promover a reflexão sobre a importância dos recursos naturais; discutir os impactos ambientais e territoriais de obras governamentais na vida da comunidade (construção de hidroelétricas, por exemplo); promover campanhas de reutilização e reciclagem; repassar informações sobre sustentabilidade ambiental e desenvolvimento.

A inserção dessa temática no âmbito das oficinas com a população usuária dos CRAS é fundamental, por possibilitar o debate sobre um direito tão pouco discutido e por ter um potencial transformador no território. Para que cada pessoa possa ser responsável pelo cuidado com o planeta são necessárias ações de sensibilização perante as consequências de hábitos insustentáveis e informação sobre como agir de modo sustentável.

Refletir sobre meio ambiente saudável como direito e bem comum coloca em debate também a relação entre os efeitos da crise ambiental e a vulnerabilidade social. Numa perspectiva de sociedade de riscos socioambientais, pessoas, famílias e comunidades em situação de vulnerabilidade social decorrente da pobreza e do precário acesso a bens e serviços também têm aumentado o risco de serem afetados, em termos físico, social, econômico ou político, no caso de uma situação desestruturante de origem natural ou antrópica (Mendes, \& Tavares, 2011). Ou seja, a vulnerabilidade social está vinculada também aos riscos ambientais, revelando que a desigualdade social aumenta a fragilidade frente a problemas e desastres ambientais. Os estudos do Painel Intergovernamental sobre Mudanças Climáticas (Intergovernmental Panel on Climate Change - IPCC) (2014) apontam que pessoas em situação de vulnerabilidade social são especialmente vulneráveis às alterações climáticas, por exemplo. Esta vulnerabilidade elevada é multifatorial. Está relacionada ao status socioeconômico e de renda e à exposição aos riscos: "riscos relacionados ao clima afetam diretamente a vida das pessoas pobres através de impactos nos meios de subsistência, reduções nas colheitas ou destruição de casas; e indiretamente por meio de, por exemplo, aumento dos preços dos alimentos e insegurança alimentar" (IPCC, 2014).

Nesta perspectiva, o trabalho social com famílias sobre a questão ambiental é duplamente necessário na área de assistência social. Possibilita a compreensão da relação entre ser humano e natureza e da importância da sustentabilidade em um espaço de aquisição e trocas de conhecimentos que podem gerar reflexão e promoção de atitudes cotidianas sustentáveis, como cessar o hábito de queimadas dos resíduos sólidos, separar resíduos orgânicos e os materiais recicláveis e dar a destinação adequada, reduzir o consumo de água, etc. Além de serem cidadãos que podem contribuir para a sustentabilidade do planeta, o público do CRAS é formado por pessoas em situação de vulnerabilidade social, na maioria das vezes decorrente da pobreza, sobre as quais a exposição aos riscos socioambientais se torna maior. Portanto, o acesso à informação sobre a relação ser humano e natureza e à vulnerabilidade socioambiental nas quais se encontram possibilita organização social frente a riscos socioambientais e mudanças territoriais, além de conferir maiores condições de argumentação e mobilização social favoráveis à sustentabilidade.

Trabalhar a temática ambiental nas oficinas com os usuários do CRAS, conduzidas preferencialmente por dois profissionais de nível superior do serviço, convida os profissionais para o diálogo interdisciplinar com as Ciências Ambientais, a fim de que essa importante possibilidade de promoção de qualidade de vida e sustentabilidade através de práticas cotidianas possa ser desenvolvida para a construção de um futuro sustentável.

Discutir a temática do meio ambiente implica lançar bases para a compreensão de que o ser humano, enquanto ser biológico e social, também está integrado aos sistemas ecológicos: "de fato, a educação ambiental toma a ecologia como pretexto para trabalhar a integridade humana. O simples fato de aprender a economizar, a reciclar, a compartilhar, a complementar, a preservar, a aceitar a diferença pode representar uma revolução no corpo do sistema social" (Catalão como citado em Gadotti, 2000, p. 85). Isso porque, ao contrariar os valores capitalistas, a educação ambiental retoma valores como a solidariedade, a cooperação, o cuidado e a valorização do ser e não do ter. 
As temáticas trabalhadas nas oficinas com as famílias dentro do âmbito do direito ao meio ambiente saudável dependem do estudo prévio do território em que cada CRAS se encontra, bem como do diálogo dos técnicos com a população atendida. Por meio da conscientização e sensibilização ambiental, pautadas em uma perspectiva sistêmica e complexa do ambiente, podem ser contemplados saberes e técnicas sobre: descarte correto dos resíduos, reciclagem e compostagem, captação da água da chuva, técnicas de reciclagem de águas cinza, bioconstrução ou construção ecológica, banheiro seco, hortas orgânicas, jardinagem e arborização, economia solidária, entre outros, que, quando aplicados, melhoram a qualidade do território e a qualidade ambiental do espaço do CRAS e seu entorno.

Oficinas sobre a construção de banheiros secos e o tratamento ecológico de águas cinzas com técnicas sustentáveis, simples e baratas podem contribuir para a diminuição do problema da falta de saneamento básico, que ainda é deficitário nas periferias, principalmente no que se refere ao afastamento de águas servidas. Segundo dados do Sistema Nacional de Informações sobre Saneamento (Brasil, 2016), 49,8\% do esgotamento sanitário não é coletado no Brasil. A falta de saneamento básico polui os recursos hídricos, o solo e o ar, e está relacionada a doenças como: diarreia, hepatite A, dengue, febre amarela, leishmaniose, malária, doença de Chagas, esquistossomose, leptospirose, tracoma, conjuntivites, doenças da pele, micoses, teníase, poliomielite, giardíase, dentre uma vasta lista de outras doenças (Brasil, 2010).

O compartilhamento de saberes sobre as técnicas de bioconstrução ou construção sustentável, que utiliza materiais locais, como a terra crua, e reaproveita materiais, como pneus, dormentes de trilho de trem, vidros de equipamentos não utilizados, pode engendrar a busca por treinamento de pedreiros locais e possibilitar a melhoria da condição habitacional em comunidades com moradias precárias.

Várias técnicas de bioconstrução podem utilizadas para construir de modo sustentável, dentre elas adobe, COB, pau-a-pique (ou taipa de mão), taipa-leve, tijolo de palha, block-in-lock, tela-palha, ferro-cimento, tijolo prensado de solocimento ou solo-cal (ou bloco de terra comprimida - BTC), superadobe, entre outras.

Quando a bioconstrução utiliza tijolos, eles são, em sua maioria, feitos com terra local, que não precisa ser transportada e queimada. Isso é importante porque a queima de mil tijolos convencionais consome $1 \mathrm{~m}^{3}$ de madeira, o que corresponde a seis árvores médias, assegura o Ministério do Meio Ambiente (Brasil, 2008), e gera desmatamento, poluição do ar, efeito estufa.

A construção com terra crua e com reaproveitamento de materiais não utilizados também favorece o menor custo com materiais da obra, se constituindo uma possibilidade de acesso à moradia pela população em situação de vulnerabilidade social.

A mobilização da comunidade em forma de mutirões de bioconstrução, em que as pessoas se unem para construir coletivamente as residências, é uma estratégia que gera economia com a mão de obra e fortalecimento do sentimento de comunidade, solidariedade e a amizade no território.

A mobilização e o envolvimento coletivo em torno dos problemas comunitários num território contribuem significativamente para o aumento do sentimento de comunidade e identidade lugar. Além de gerar apoio mútuo, a participação comunitária estimula processos de decisão a favor da comunidade que provocam mudança social (Elvas \& Moniz, 2010).

Para os indivíduos, numa primeira instância, e para a comunidade, os níveis de qualidade e satisfação de vida funcionam como experiências e recursos positivos para proteger a saúde biopsicossocial. A participação activa na comunidade, o envolvimento efectivo em organizações políticas e a mobilização comunitária em torno dos problemas sociais, afastam por completo níveis baixos de satisfação de vida, os quais estão mais relacionados com situações de depressão, rejeição pessoal, solidão, comportamentos agressivos, consumo de álcool e abuso de substâncias químicas (Elvas \& Moniz, 2010, p. 462).

O fomento à organização de catadores de materiais recicláveis, que é uma forma de trabalho informal comum em territórios em vulnerabilidade social, em cooperativas de reciclagem, a fim de potencializar a renda e gerar maior qualidade de vida, é outra iniciativa que pode ser levada em conta no planejamento das oficinais pelos técnicos de referência que desenvolvem o trabalho social com famílias no CRAS.

Oficinas sobre o plantio em hortas orgânicas é outra importante estratégia de enfrentamento da fome e escassez de alimentos, uma vez que a agricultura pode garantir segurança alimentar e nutrição de pessoas em 
vulnerabilidade social. Além disso, gera conhecimento e consciência da importância do consumo de alimentos saudáveis e sem contaminação por agrotóxicos.

O uso inadvertido de agrotóxicos prejudica o planeta como um todo, alterando a saúde e a qualidade de vida de todos os seres vivos. O Instituto Nacional de Câncer-INCA (2015) adverte que a intoxicação por agrotóxicos pode ocorrer de forma aguda ou crônica, este último ocorre quando o indivíduo é exposto a pequenas quantidades por longos períodos. No primeiro caso, logo após o contato, podem surgir sintomas como vômitos, diarreias, irritação nos olhos e na pele, coceira, dificuldades respiratórias, convulsões e morte. Na intoxicação crônica, há uma infinidade de efeitos, como redução do sistema imunológico, prejuízos ao sistema nervoso central, desregulação endócrina, infertilidade, aborto, malformações e câncer (INCA, 2015).

O trabalho educativo sobre hortas pode ainda estimular o plantio de hortas familiares ou comunitárias que fortalecem as relações interpessoais, contribuem para a segurança alimentar e suscitam a comercialização dos excedentes, gerando incremento da renda familiar.

Desenvolver intervenções funcionais e estéticas no ambiente, como bioconstrução, a jardinagem e o plantio de árvores, contribui tanto para a sustentabilidade ecológica quanto para a saúde psicológica da comunidade, pois as condições do ambiente de vida desencadeiam efeitos psicológicos.

Um estudo recente realizado por Younan, Tuvlad, Li, Wu, Lurmann, Franklin, et al. (2016) constatou que residir em bairros com maior arborização diminui a incidência de comportamentos agressivos nos jovens. A diminuição da violência favorece a segurança, o bem-estar e o vínculo positivo com o território. Assim como há evidências de aumento da sensação de bem-estar em ambientes com mais áreas verdes, pesquisas identificaram relação entre depressão e ambientes subjetivos ansiogênicos, feios, ou lugares onde as pessoas não se reconhecem, com os quais não se identificam (Déoux, \& Déoux, 1996).

A identificação com o ambiente onde se vive, relacionada com a sensação de acolhida e segurança que este espaço transmite, é imprescindível para o surgimento do sentimento de pertencimento àquele ambiente, constatam as pesquisas de Psicologia Ambiental. Valera e Pol (1994) ressaltam que os vínculos humanos com os lugares são tão importantes para o indivíduo quanto os vínculos que estabelece com pessoas ou grupos. O vínculo afetivo positivo com os lugares se torna a base para o cuidado com o território e para o bem-estar pessoal sentido naquele espaço.

Além disso, o sentimento de pertença a um ou mais entornos concretos é um dos processos que constitui a identidade do sujeito (Valera, \& Pol, 1994). Viver em locais esteticamente mais bonitos, mais floridos e verdes, permeados pelo sentimento de comunidade, onde se possam criar vínculos positivos, potencializa a autoestima das pessoas, componente psicológico fundamental para a autonomia e a transformação social.

O trabalho em grupo sobre essas temáticas visa ser uma intervenção emancipatória, na perspectiva da Psicologia Social Comunitária, não assistencialista, mas comprometida com o desenvolvimento da consciência e da autonomia de populações marginalizadas social e economicamente, como propunha Lane (1995).

Os territórios de abrangência do CRAS costumam ser periféricos, com pouca infraestrutura e esparsa presença de verde. Nesse sentido, incitar a promoção de mudanças físicas nos ambientes no sentido de torná-los mais sustentáveis é uma estratégia para a promoção de qualidade de vida e bem-estar para a população.

É importante ressaltar que as oficinas devem valorizar os saberes populares da comunidade, bem como podem contar com a participação de técnicos especializados em determinadas temáticas abordadas. Ademais, o apoio dos gestores públicos à equipe técnica do CRAS é condição fundamental para a qualidade e a abrangência do trabalho social sobre o direito ao meio ambiente saudável.

Tendo em vista o exposto, vislumbra-se um horizonte de inúmeras possibilidades de intervenções sobre a questão ambiental no CRAS, capazes de promover a compreensão de que o ser humano faz parte da natureza, que a saúde humana depende do equilíbrio ecológico e que novas formas de ser e viver no planeta são possíveis, com cuidado ao meio ambiente e às pessoas.

\section{Considerações finais}

Um dos grandes desafios da humanidade na contemporaneidade é a concretização dos princípios da sustentabilidade que garantam a preservação do meio ambiente, a justiça social e qualidade de vida das pessoas. Embora a ciência venha há décadas alertando sobre a degradação e depredação da natureza, muito 
é preciso avançar no desenvolvimento da consciência ecológica e de mudanças sociais, políticas e econômicas que garantam a sustentabilidade.

Sendo os problemas ambientais, na verdade, problemas humano-ambientais, ocasionados pela ação humana, são imprescindíveis ações de educação, debate e participação social voltadas para a temática ambiental, pautados em uma perspectiva complexa de interdependência entre ser humano e natureza.

No Brasil, o reconhecimento do direito ao meio ambiente saudável no SUAS como temática de discussão nas oficinas com famílias nos CRAS é uma importante possibilidade de trabalho de conscientização ecológica e promoção de qualidade de vida e sustentabilidade. É um direito de todo cidadão brasileiro ter acesso à água limpa, ar puro, solo fértil e saudável, alimentos sem contaminantes químicos, proteção da biodiversidade do território, áreas verdes públicas para lazer e saúde da população e a ambientes construídos que favoreçam a qualidade de vida. $\mathrm{E}$ a busca pela efetivação deste direito depende da consciência ecológica, que fundamenta práticas sustentáveis, imprescindíveis para a qualidade de vida no território e a sustentabilidade da vida no planeta.
Ademais, capacitar as pessoas para a produção de parte dos alimentos consumidos, a participação na construção de suas casas, a melhoria da paisagem de seu entorno, através de aquisição de conhecimentos para desenvolver tais atividades, dentre outras que podem ser abordadas, constitui uma intervenção com grande potencial de propiciar segurança alimentar, dignidade, qualidade de vida, autonomia e autoestima à população.

Nesse sentido, é fundamental que os profissionais de nível superior integrantes da equipe de referência dos CRAS, dentre eles o (a) psicólogo (a), insiram a busca pela sustentabilidade como um valor inerente às suas práticas e recebam formação continuada que os potencialize para a facilitação e coordenação de oficinas com famílias sobre o direito de todo cidadão brasileiro ao meio ambiente saudável.

O trabalho social com famílias sobre esta temática, pouco trabalhada com pessoas em situação de vulnerabilidade social, é importante tanto no sentido de informar e sensibilizar quanto de estimular a participação social dos usuários na buscar por melhoria da qualidade de vida no seu território, com vistas à ampliação da democracia e à transformação da realidade.

\section{Referências}

Brandão, C. R. (2007). O vôo da arara-azul: Escritos sobre a vida, a cultura e a educação ambiental. Campinas, SP: Armazém do Ipê.

Brasil. Fundação Nacional de Saúde. (2010). Impactos na saúde e no sistema único de saúde decorrentes de agravos relacionados a um saneamento ambiental inadequado. Brasília, DF: o autor.

Brasil. Ministério das Cidades. (2016). Sistema nacional de informações sobre saneamento: Diagnóstico dos serviços de água e esgotos - 2014. Brasília, DF: o autor.

Brasil. Ministério do Desenvolvimento Social. (2004). Política nacional de assistência social e norma operacional básica. Brasília, DF: o autor. Recuperado de http://www.mds.gov.br/webarquivos/publicacao/assistencia_ social/Normativas/PNAS2004.pdf

Brasil. Ministério do Desenvolvimento Social. (2015). Sistema único de assistência social completa 10 anos. Portal Brasil, 27 abr. 2005. Recuperado de http://www.brasil.gov.br/cidadania-e-justica/2015/04/sistema-unico-de-assistencia-social-completa-10-anos

Brasil. Ministério do Desenvolvimento Social e Combate à Fome. (2005). Norma operacional básica NOB/SUAS: Construindo as bases para a implantação do Sistema Único de Assistência Social. Brasília, DF: o autor. Recuperado de http://www.assistenciasocial.al.gov.br/sala-de-imprensa/arquivos/NOB-SUAS.pdf

Brasil. Ministério do Desenvolvimento Social e Combate à Fome. (2009). Orientações técnicas: Centro de referência de assistência social - CRAS. Brasília, DF: o autor.

Brasil. Ministério do Desenvolvimento Social e Combate à Fome. (2012). Orientações técnicas sobre o PAIF: Trabalho social com famílias do serviço de proteção e atendimento integral à família - PAIF (vol. 2). Brasília, DF: o autor.

Brasil. Ministério do Meio Ambiente. (2008). Curso de bioconstrução. Brasília, DF: o autor.

Brasil. Senado Federal. (1988). Constituição da República Federativa do Brasil. Brasília, DF: o autor. 
Psicologia: Ciência e Profissão 2019 v. 39, e188719, 1-15.

Braun, R. (2005). Novos paradigmas ambientais: Desenvolvimento ao ponto sustentável (2a ed.). Petrópolis, RJ: Vozes.

Carvalho, M. A. B. (2013). De frente para o espelho: Ecopsicologia e sustentabilidade (Tese de doutorado). Universidade de Brasília, Brasília, DF, Brasil.

Cavalcanti, C. (2004). Uma tentativa de caracterização da economia ecológica. Ambiente \& Sociedade, 7(1), 149-156. https://doi.org/10.1590/S1414-753X2004000100009

Comissão Mundial sobre Meio Ambiente e Desenvolvimento - CMMAD. (1988). Nosso futuro comum (Relatório Brundtland). Rio de Janeiro, RJ: Fundação Getúlio Vargas.

Déoux, S., \& Déoux, P. (1996). Ecologia é a saúde. Lisboa: Instituto Piaget.

Di Giovanni, G. (1998). Sistemas de proteção social: Uma introdução conceitual. In M. A. Oliveira (Org.), Reforma do estado e políticas de emprego no Brasil (pp. 9-29). Campinas, SP: Unicamp.

Elvas S., \& Moniz, M. J. V. (2010). Sentimento de comunidade, qualidade e satisfação de vida. Análise Psicológica, 28(3), 451-464. https://doi.org/10.14417/ap.312

Freitas, M. F. Q. (2012). Intervenção psicossocial e compromisso: Desafios às políticas públicas. In A. M. Jacó-Vilela, \& L. Sato (Orgs), Diálogos em psicologia social (pp. 370-386). Rio de Janeiro, RJ: Centro Edelstein de Pesquisas Sociais.

Gadotti, M. (2000). Pedagogia da Terra. São Paulo, SP: Peirópolis.

Global Ecovillage Network - GEN. (2011). Global ecovillage network. Findhorn: o autor. Recuperado de https:// ecovillage.org/

Góis, C.W. L. (1993). Noções de psicologia comunitária. Fortaleza, CE: Universidade Federal do Ceará.

Instituto Nacional de Câncer José Alencar Gomes da Silva - INCA. (2015). Posicionamento do instituto nacional de câncer José Alencar Gomes da Silva acerca dos agrotóxicos. Brasília, DF: o autor. Recuperado de http://www1.inca. gov.br/inca/Arquivos/comunicacao/posicionamento_do_inca_sobre_os_agrotoxicos_06_abr_15.pdf

Intergovernmental Panel on Climate Change - IPCC. (2014). Sumário do relatório do IPCC para os tomadores de decisão do quinto relatório do grupo de trabalho II, 2014 (Iniciativa Verde, Trad.). São Paulo, SP: Iniciativa Verde. Recuperado de http://www.iniciativaverde.org.br/biblioteca-nossas-publicacoes.php

Lane, S. T. M. (1995). Avanços da psicologia social na América Latina. In S. T. M. Lane, \& B. B. Sawaia, Novas veredas da psicologia social (pp.67-81). São Paulo, SP: EDUC.

Lane, S. T. M. (2000). A psicologia social na América Latina: Por uma ética do conhecimento. In R. H. F. Campos, \& P. Guareschi, Psicologia social: A perspectiva latino-americana (pp. 58-69). Petrópolis, RJ: Vozes.

Leff, E. (2009). Ecologia, capital e cultura: A territorialização da racionalidade ambiental. Petrópolis, RJ: Vozes.

Lei No 8.742, de 7 de dezembro de 1993. Dispõe sobre a organização da Assistência Social e dá outras providências. Diário Oficial da União, 8 dez. 1993.

Loureiro, C. F. B. (2012). Sustentabilidade e educação: Um olhar da ecologia política. São Paulo, SP: Cortez.

Mendes, J. M., \& Tavares, A. O. (2011). Risco, vulnerabilidade social e cidadania. Revista Crítica de Ciências Sociais, (93), 5-8.

Padoin, I. G., \& Virgolin, I. W. C. (2010). A vulnerabilidade social como uma dificuldade à participação política. Seminário Institucional de Ensino, Pesquisa e Extensão da UNICRUZ, Cruz Alta, RS, Brasil, 15.

Pereira, T. D. (2010). Política nacional de assistência social e território: Enigmas do caminho. Revista Katálysis, 13(2), 191-200. https://doi.org/10.1590/S1414-49802010000200006

Pinheiro, J. Q. (1997). Psicologia ambiental: A busca de um ambiente melhor. Revista Estudos de Psicologia, 2(2), 377-398. https://doi.org/10.1590/S1413-294X1997000200011

Rattner, H. (2009). Meio ambiente, saúde e desenvolvimento sustentável. Ciência e Saúde Coletiva, 14(6), 1965-1971. https://doi.org/10.1590/S1413-81232009000600002

Resolução № 17, de 20 de junho de 2011. Ratificar a equipe de referência definida pela norma operacional básica de recursos humanos do sistema único de assistência social - NOB-RH/SUAS e reconhecer as categorias profissionais de nível superior para atender as especificidades dos serviços socioassistenciais e das funções essenciais de gestão do Sistema Único de Assistência Social - SUAS. Diário Oficial da União, 21 jun. 2011. 
Roszak, T. (1995). Where psyche meets gaia. In T. Roszak, M. E. Gomes, A. D. Kanner (Orgs), Ecopsychology: Restoring the earth, healing the mind (pp. 1-17). San Francisco, CA: Sierra Club.

Sachs, I. (2007). Rumo à ecossocioeconomia: Teoria e prática do desenvolvimento. São Paulo, SP: Cortez.

Valera, S., \& Pol, E. (1994). El concepto de identidad social urbana: Una aproximación entre la psicologia social y la psicologia ambiental. Anuario de Psicologia, (62), 5-24.

Younan, D., Tuvlad, C., Li, L., Wu, J., Lurmann, F., Franklin, M. et al. (2016). Environmental determinants of aggression in adolescents: Role of urban neighborhood greenspace. Journal of the American Academy of Child \& Adolescent Psyquiatry, 55(7), 591-601. https://doi.org/10.1016/j.jaac.2016.05.002

\section{Kelly Daiane Savariz Bôlla}

Psicóloga. Mestre e Doutora em Ciências Ambientais e pesquisadora do Laboratório de Sociedade, Desenvolvimento e Meio Ambiente (LABSDMA) da Universidade do Extremo Sul Catarinense (UNESC), Criciúma - SC. Brasil.

E-mail: kellybolla@hotmail.com

iD http://orcid.org/0000-0002-6593-546X

\section{Geraldo Milioli}

Sociólogo. Professor e Pesquisador do Programa de Pós-Graduação em Ciências Ambientais (PPGCA) e Coordenador do Laboratório de Sociedade, Desenvolvimento e Meio Ambiente (LABSDMA) da Universidade do Extremo Sul Catarinense (UNESC), Criciúma - SC. Brasil.

E-mail: gmi@unesc.net

iD https://orcid.org/0000-0001-5224-2042

Endereço para envio de correspondência:

Av. Universitária, 1105, Bloco P, sala 7 - Bairro Universitário, CEP: 88806-000 - Criciúma - SC

Recebido 04/12/2017

Reformulado 30/04/2018

Aceito 04/06/2018

Received 12/04/2017

Reformulated $04 / 30 / 2018$

Approved 06/04/2018

Recibido 04/12/2017

Reformulado 30/04/2018

Aceptado 04/06/2018

Como citar: Bôlla, K. D. S. , \& Milioli, G. (2019). A questão ambiental no CRAS: promoção de qualidade de Vida e Sustentabilidade. Psicologia: Ciência e Profissão, 39, 1-15. https://doi.org/10.1590/1982-3703003188719

How to cite: Bôlla, K. D. S. , \& Milioli, G. (2019). The environmental issue in CRAS: perspectives for promotion of quality of life and sustainability. Psicologia: Ciência e Profissão, 39, 1-15. https://doi.org/10.1590/1982-3703003188719

Como citar: Bôlla, K. D. S. , \& Milioli, G. (2019). La cuestión ambiental en el CRAS: perspectivas para promover la calidad de Vida y la sostenibilidad. Psicologia: Ciência e Profissão, 39, 1-15. https://doi.org/10.1590/1982-3703003188719 